\title{
Structural Characterization of the Immunoactive and Antiviral Water-solubilized Lignin in an Extract of the Culture Medium of Lentinus edodes Mycelia (LEM)
}

\author{
Harumi Suzuki, Kenji Iryama, ${ }^{*}$ Osamu Yoshida, ${ }^{* *}$ \\ Sunao Yamazaki, Naoki Yamamoto** \\ and Shozo TODA \\ Department of Agricultural Chemistry, and \\ * Department of Forest Products, The University of Tokyo, \\ Bunkyo-ku, Tokyo 113, Japan \\ ** Department of Virology and Parasitology, Yamaguchi University \\ School of Medicine, 1144 Kogushi, Ube, \\ Yamaguchi 755, Japan \\ Received August 21, 1989
}

\begin{abstract}
The active principle of EP3, a fraction from an extract of the culture medium of Lentinus edodes mycelia (LEM), which activates murine macrophages, causes proliferation of bone marrow cells, and inhibit the replication of Human Immunodeficiency Virus in vitro, was characterized as a watersolubilized lignin. The detailed structural feature of this water-solubilized lignin was investigated and shown to be a highly condensed and polycarboxylated lignin which is denatured and solubilized by Lentinus edodes from bagasse. The water-solubilized lignin itself was confirmed to have both immunological activities and the antiviral activity.
\end{abstract}

LEM is a whole extract of the mycelial culture of a Japanese edible mushroom, Lentinus edodes, grown in a solid medium of sugar-cane bagasse and defatted rice bran. ${ }^{1)}$ LEM and its purified fractions have antiviral activities and immunomodulating functions. LEM inhibits infection by tobacco mosaic virus by blocking the initial stage of the replicative cycle, ${ }^{21}$ and inhibits the infectivity of human immunodeficiency virus (HIV) and cytopathic effects on the virus-infected cells in vitro. $^{3,4)}$ Very recently, LEM was reported to be effective in AIDS therapy by oral administration. ${ }^{5}$ LEM modulates immunological responses by enhancement of IL-1 production, ${ }^{6)}$ activation of murine macrophage functions, ${ }^{7)}$ promotion of proliferation of murine bone marrow cells, ${ }^{8)}$ suppression of the proliferation of rat ascite hepatoma AH414 and its hepatocarcinogenesis by intra-peritoneal administration, ${ }^{9}$ and promotion of seroconversion from $\mathrm{HBe}$ antigen to anti-HBe antibody in chronic hepatitis $\mathrm{B}$ patients by oral adminis- tration without any side effects. ${ }^{10)}$

Our studies on the immunostimulating ability of LEM showed that EP3, a fraction of LEM, augmented glucose consumption of macrophages and induced proliferation of bone marrow cells in vitro. ${ }^{8)}$ Recently, we showed that EP3 and its lower molecular weight fraction (EPS4) inhibited the infectivity and cytopathic effects of HIV in vitro, and further presumed that a major component of EP3 and EPS4 was a water-solubilized lignin. ${ }^{4)}$ In this paper, we have analyzed the structure of the active substance in EP3, and found that the highly condensed and carboxylated lignin is responsible for the immunological and antiviral activities.

\section{Materials and Methods}

\section{Materials.}

Preparation of LEM. LEM (Noda Shokuhin Kogyo Co., Ltd., Chiba) was prepared by the previously reported method. ${ }^{1)}$ Lentinus edodes (Japanese edible mushroom, 
shitake) mycelia were cultured in a solid medium composed mainly of sugar-cane bagasse for 3 months, then the whole medium containing mycelia was extracted by hot water. The extract was filtered and freeze-dried as LEM.

Preparation of EP3. Fractionation of LEM was done by two steps (ethanol precipitation and hydrophobic chromatography) as described previously. ${ }^{4)}$ Briefly, LEM was dissolved in a 10-fold excess of water and cold ethanol was added to the solution. A $37.5 \%$ ethanol soluble, $50 \%$ insoluble fraction was designated as neoPPT1. NeoPPT1 was adsorbed to Phenyl Sepharose CL-4B (Pharmacia, Sweden) column, and the fraction eluted by $75 \%$ ethyleneglycol solution followed by dialysis was designated as EP3. The most active fraction, EP3, was used throughout this study.

Protein digestion. EP3 $(100 \mathrm{mg})$ was dissolved in $20 \mathrm{ml}$ of $50 \mathrm{~mm}$ borate buffer ( $\mathrm{pH} 7.8$ ) containing $1 \mathrm{mM} \mathrm{CaCl}_{2}$ and $5 \mathrm{mg}$ of Pronase E (Sigma, Streptomyces griseus) was added to the solution and incubated at $37^{\circ} \mathrm{C}$ for 3 days. The $\mathrm{pH}$ of solution was kept at 7.8 and $5 \mathrm{mg}$ of Pronase $\mathrm{E}$ was added every $24 \mathrm{hr}$ during the incubation. The digested mixture was then boiled for $10 \mathrm{~min}$ and freeze-dried to give the proteolyzed lignin (EP3-PR)

Elimination of carbohydrates. ${ }^{11)} \mathrm{EP} 3(25 \mathrm{mg})$ was dissolved in $0.5 \mathrm{ml}$ of $72 \%$ (w/w) $\mathrm{H}_{2} \mathrm{SO}_{4}$ solution, and digested at $30^{\circ} \mathrm{C}$ for $1 \mathrm{hr}$. After addition of $19.5 \mathrm{ml}$ of water, the mixture was autoclaved at $121^{\circ} \mathrm{C}$ for $1 \mathrm{hr}$. Then the solution was neutralized, dialyzed against water and freeze-dried to obtain a carbohydrate-free specimen (EP3KL).

Oxidative degradation of lignin by sodium chlorite. Lignin was degraded oxidatively under the conditions for holocellulose preparation. ${ }^{12}$ Acetic acid $(10 \mu)$ and $\mathrm{NaClO}_{2}(50 \mathrm{mg})$ were added to the solution of EP3 $(10 \mathrm{mg} /$ $7.5 \mathrm{ml}$ water), and the solution was digested at $70^{\circ} \mathrm{C}$ for $1 \mathrm{hr}$ with gentle shaking. This procedure was repeated 4 times. Then, the solution was desalted by Sephadex G-10 column chromatography and freeze-dried. Lignindecomposed EP3 (EP3-DL) was obtained in $90 \%$ yield.

\section{Assay methods.}

Assay for morphological change and glucose consumption of macrophages. Peritoneal resident macrophages $\left(1 \times 10^{5}\right)$ obtained from male ddY mice were cultured in the absence or presence of various concentrations of samples at $37^{\circ} \mathrm{C}$ on a 96-well microplate. Morphological changes (spreading) of macrophages were observed by a phase-contrast microscope after $24 \mathrm{hr}$ of culture. After 4 days of culture, glucose consumption was estimated from glucose remaining in the culture supernatant by the colorimetric method using glucose oxidase.

Assay for proliferation of bone marrow cells. Bone marrow cells $\left(1.5 \times 10^{5}\right)$ obtained from thighbones of male C57BL/6 mice were cultured with various concentrations of samples for 4 days. Proliferation of the cells was evaluated by the incorporation of $\left[{ }^{3} \mathrm{H}\right]$ thymidine in the usual manner.
Assay for HIV antigen expression. Anti-HIV activity was evaluated by the inhibition of the cell surface expression of HIV-specific antigens on HIV infected MT-4 cells as described previously. ${ }^{3)}$ HIV infected MT-4 cells $\left(10^{4}, \mathrm{MOI} 0.01\right)$ were cultured with various concentrations of samples for 4 days, and the expression of virus antigen was measured by indirect immunofluorescence using antiHIV antibody positive plasma. At the same time, the number of viable cells on day 4 was counted by trypan blue dye exclusion to evaluate the activity against HIVinduced cytopathic effects.

\section{Chemical analysis.}

Protein content of EP3. EP3 was digested in $6 \mathrm{~N} \mathrm{HCl}$ in the usual manner and the protein content of EP3 was determined by amino acid analysis using a Hitachi 835 amino acid analyzer.

Determination of neutral sugar and uronic sugar. After EP3 was hydrolyzed with $3 \%$ sulfuric acid, ${ }^{11}$ the Somogyi-Nelson method was applied to determine neutral sugar content of EP3. Uronic sugar was determined by the carbazole- $\mathrm{H}_{2} \mathrm{SO}_{4}$ method.

Determination of phenolic hydroxyl groups. Phenolic hydroxyl groups (free form) in EP3 were determined by the $\Delta \varepsilon$ method. ${ }^{131}$

Determination of lignin. ${ }^{\text {4) }}$ EP3 (2 mg) was placed in a glass reaction bottle with a solution of $25 \%(\mathrm{w} / \mathrm{w})$ acetyl bromide in acetic acid $(5 \mathrm{ml})$ containing perchloric acid $(70 \%, 0.2 \mathrm{ml})$. After digestion at $70^{\circ} \mathrm{C}$ for $30 \mathrm{~min}$ with gentle shaking, the solution was transferred to a $100 \mathrm{ml}$ volumetric flask containing $2 \mathrm{M} \mathrm{NaOH}(20 \mathrm{ml})$ and acetic acid $(25 \mathrm{ml})$. Then the solution was made up to $100 \mathrm{ml}$ with acetic acid and the absorbance was measured at $280 \mathrm{~nm}$. Lignin content was determined by using the specific absorption coefficient of $20.0 \mathrm{~g}^{-1} \cdot 1 \cdot \mathrm{cm}^{-1}$.

Alkaline nitrobenzene oxidation. ${ }^{[5]}$ Sodium hydroxide $(2 \mathrm{M}, 4 \mathrm{ml})$ and nitrobenzene $(0.25 \mathrm{ml})$ were added to EP3, and the mixture was heated at $180^{\circ} \mathrm{C}$ for $4 \mathrm{hr}$ in a stainiess steel vessel. 3-Ethoxy-4-hydroxybenzaldehyde was added to the reaction mixture as an internal standard and the mixture was extracted three times with dichloromethane $(30 \mathrm{ml}$ each) to remove nonphenolic matters. The aqueous layer was acidified to $\mathrm{pH} 1$ and extracted twice with dichloromethane $(30 \mathrm{ml})$ and once with diethylether. The organic layer was washed once with water, dehydrated with anhydrous $\mathrm{Na}_{2} \mathrm{SO}_{4}$, and dried in vacuo. The extract was trimethylsilylated and analyzed by gas-liquid chromatography with an OV101 bonded column $(50 \mathrm{~m} \times$ $0.25 \mathrm{~mm}$ ) in a mode of linearly-increasing temperature from 180 to $250^{\circ} \mathrm{C}$ at the rate of $5^{\circ} \mathrm{C} / \mathrm{min}$ after keeping at $180^{\circ} \mathrm{C}$ for $10 \mathrm{~min}$.

Determination of carboxyl groups by amidation. ${ }^{16)} \mathrm{EP} 3$ $(100 \mathrm{mg}$ ) was dissolved in $10 \mathrm{ml}$ of water and $3 \mathrm{mmols}$ of glycine methyl ester were added to the solution. The mixture was adjusted to $\mathrm{pH} 4.75$ and $12.5 \mathrm{ml}$ of the aqueous solution containing 2 mmols of 1 -ethyl-3-(3dimethylaminopropoyl)carbodiimide (EDC) were added. 
After the solution was kept stirred for $4 \mathrm{hr}$ at the same $\mathrm{pH}$ at room temperature, it was dialyzed against water and freeze-dried to give the amidated product designated EP3GME. The IR spectrum of EP3-GME showed all of carboxyl groups were converted to amide. The carboxyl content was calculated from the increased nitrogen content.

$U V, I R$, and NMR analyses. UV spectra were taken by a Shimadzu UV-200 spectrophotometer. IR spectra were recorded as $\mathrm{KBr}$ tablets on a Shimadzu IR-435 infrared spectrophotometer. CP/MAS NMR spectra were taken with a Bruker MSL-400 spectrometer.

\section{Results}

Spreading of macrophages induced by EP3

As shown in Fig. 1, EP3 induced the morphological change (spreading) of cultured macrophages at concentrations of $\geq 25 \mu \mathrm{g} / \mathrm{ml}$. This change began to occur after $1 \mathrm{hr}$ of culture, and reached a maximum at $24-48 \mathrm{hr}$. Well-known macrophage activators such as lipopolysaccharide and polyI : $\mathrm{C}$ did not induce such morphological changes (data not shown).
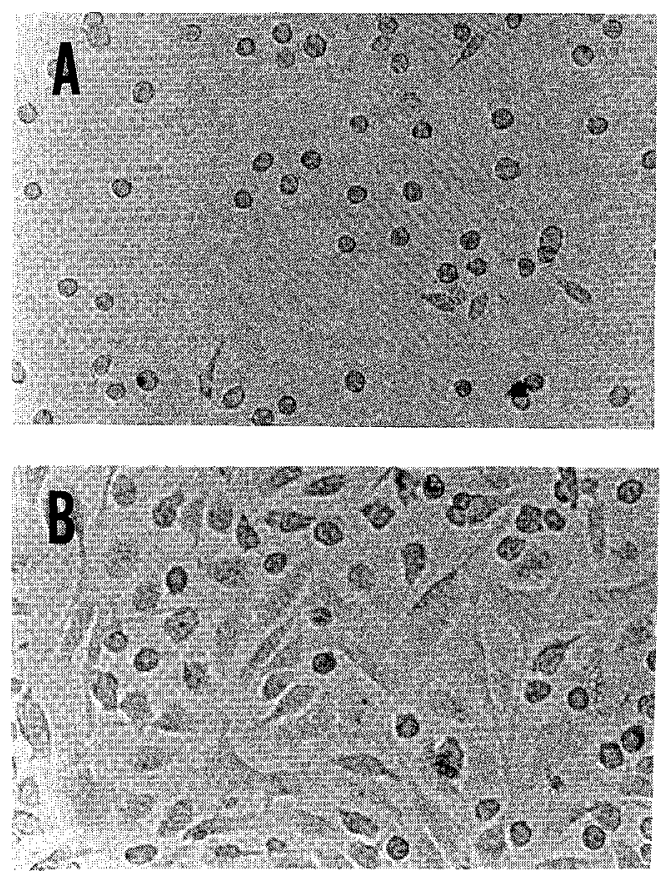

Fig. 1. Morphological Change of Murine Peritoneal Resident Macrophages Non-stimulated (A) and Stimulated by $200 \mu \mathrm{g} / \mathrm{ml}$ of EP3 (B) for $24 \mathrm{hr}$.

\section{Characteristics of EP3}

EP3 was further fractionated. The results from the gel filtration column chromatography (Sephacryl S-300, Pharmacia, see Fig. 4) and anion exchange column chromatography (DEAE-Sephacel, Pharmacia, data not shown) of EP3 suggested that the active substance in EP3 might be a highly dispersive polymer having wide molecular weight distribution and strong anionic charges. EP3 contained 3.2\% protein, $12.2 \%$ neutral sugar and $3.7 \%$ uronic acid. The elemental analysis of EP3 gave C, $44.6 \% ; \mathrm{H}, 4.68 \% ; \mathrm{N}, 1.74 \%$; and ash, $5.7 \%$.

\section{Determination of lignin}

EP3 contained about $80 \%$ of unknown organic matter which was neither proteins nor sugars. Due to strong UV absorption at $280 \mathrm{~nm}$, brownish color, high hydrophobicity, and above all high unsaturation shown in an extremely low content of hydrogen in the elemental analysis, the main component of EP3 was deduced to be lignin. The lignin content of EP3 was $81.1 \%$ by the acetyl bromide method ${ }^{14\}}$ which is based on absorption specific to the aromatic rings of lignin. ${ }^{17)}$

\section{$I R$ and $N M R$ analyses}

The IR spectrum of EP3 (solid line in Fig. 2) showed typical absorptions of lignin: primary alcohol ether $\left(1030 \mathrm{~cm}^{-1}\right)$, secondary alcohol ether $\left(1085 \mathrm{~cm}^{-1}\right)$, syringyl nucleus $(1120$, 1220 , and $\left.1325 \mathrm{~cm}^{-1}\right)$, guaiacyl nucleus $(1270$ $\left.\mathrm{cm}^{-1}\right)$, aromatic ring $(1425,1505$, and 1600 $\left.\mathrm{cm}^{-1}\right)$, carboxylate $\left(1590 \mathrm{~cm}^{-1}\right)$, and cinnamic

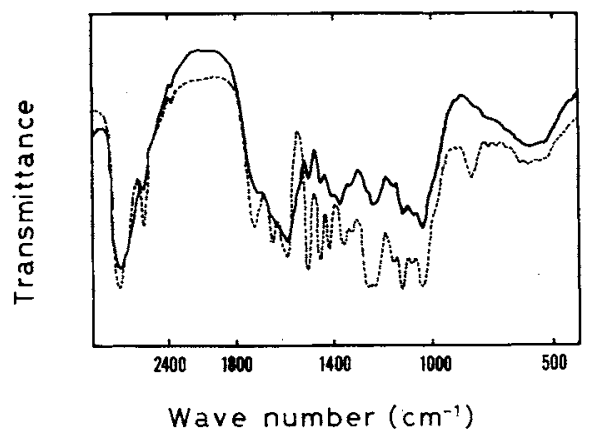

Fig. 2. IR Spectra of EP3 (solid line) and Wheat Internode Milled Wood Lignin (dashed line). 


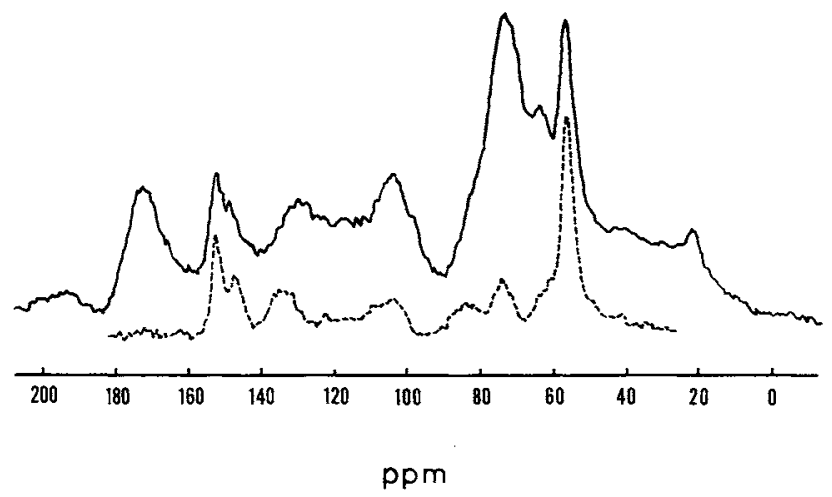

Fig. 3. $\mathrm{CP} / \mathrm{MAS}^{13} \mathrm{C}-\mathrm{NMR}$ Spectra of EP3 (solid line) and Angiosperm Milled Wood Lignin (dashed line).

acid ester $\left(1740 \mathrm{~cm}^{-1}\right)$. The last ester band is also characteristic of Gramineae lignocellulose. Milled wood lignin ${ }^{18}$ isolated from wheat internodes (dashed line in Fig. 2) gave quite a similar spectrum except that EP3 has major absorption around $1590 \mathrm{~cm}^{-1}$ due to carboxylate, and does not have one at 830 $\mathrm{cm}^{-1}$ due to the two adjacent aromatic ring hydrogens.

EP3 was analyzed by a cross polarization/ magic angle spinning ${ }^{13} \mathrm{C}-\mathrm{NMR}$ (CP/MAS NMR). As shown in Fig. 3, EP3 (solid line) and milled wood lignin (dashed line) isolated from angiosperm wood ${ }^{18)}$ gave quite similar signals: methoxyls (55 ppm), carbohydrates $(60-85 \mathrm{rpm})$, aromatic carbons (100-140 ppm), and oxygenated aromatic carbons (centered at $150 \mathrm{ppm}$ ). The two large signals characteristic of the EP3 lignin were assigned to carboxyl groups (170 ppm) and carbohydrates $(60-80 \mathrm{ppm})$. These spectral data suggested that the major component of EP3 is the carboxylated lignin of Gramineae-like origin.

\section{Alkaline nitrobenzene oxidation}

To analyze the aromatic structures of EP3, alkaline nitrobenzene oxidation was performed. ${ }^{15)}$ Benzaldehyde and corresponding acid derivatives produced were determined by gasliquid chromatography (yield $\% \mathrm{w} / \mathrm{w}$ of EP3): $p$-hydroxybenzaldehyde $(0.55 \%)$, vanillin $(0.77 \%)$, syringaldehyde $(1.96 \%), p$-hydroxybenzoic acid $(0.45 \%)$, vanillic acid $(0.72 \%)$, and syringic acid $(0.94 \%)$. Traces of $p$-coumaric and ferulic acids were also detected. These results suggest three interesting characteristics of EP3. First, the molar ratio of syringyl nuclei to guaiacyl ones (S/V) of EP3 lignin (1.67) was almost the same as that of the original bagasse lignin (1.6-1.8). ${ }^{19)}$ Furthermore the presence of cinnamic acids in the oxidation products is a direct evidence that lignin in EP3 originated from bagasse (Gramineae) lignin. Secondly, the total yield of aldehydes and acids was only $5.45 \%$ based on EP3 or $6.7 \%$ based on the acetyl bromide lignin, extremely low compared to that of native lignin, which is usually $15-25 \%{ }^{19}$ ) This suggested that lignin in EP3 has a highly condensed structure with many $\mathrm{C}-\mathrm{C}$ bonds bridging among phenylpropane units and therefore cannot produce benzaldehydes and benzoic acids by the alkaline nitrobenzene oxidation. ${ }^{15}$ ) Lastly, the total yield of benzoic acids $(2.1 \%)$ is unexpectedly high, since native lignin has no benzoic carboxyl groups and gives only a slight trace of benzoic acids which are produced by the Cannizzaro reaction from the corresponding aldehydes during alkaline nitrobenzene oxidation. ${ }^{20)}$ The unexpectedly high yield of benzoic acids by this oxidation shows that chromophores which yield benzoic acids are present in considerable numbers in EP3 lignin.

These results clearly show that lignin in EP3 originated from bagasse lignin, but it has been converted into highly condensed and highly 
denatured forms by having a great number of carboxyl groups introduced by Lentinus edodes.

\section{Analysis of carboxyl groups}

All of the above data showed that EP3 contains a considerable amount of carboxyl groups, which endow EP3 with high watersolubility. The content of carboxyl groups in EP3 was determined by a new method using amide formation. ${ }^{16)}$ EP3 was coupled with glycine methyl ester (GME) in the presence of carbodiimide and the resulted amide derivative (designated EP3-GME) showed a newly appeared primary amide ( $-\mathrm{CONH}-$ ) band at $1650 \mathrm{~cm}^{-1}$ in place of the strong carboxylate band at $1590 \mathrm{~cm}^{-1}$ in the IR spectra, indicating that carboxylate in EP3 was almost completely amidated. This was also supported by the fact that the solubility of EP3-GME in water reduced to $0.2 \%$ of that of EP3. The nitrogen content of EP3-GME increased to $4.60 \%$ compared to that of EP3 $(1.74 \%)$, and this increase of nitrogen corresponded to the incorporation of one atom of nitroge $n$ into one carboxyl group. The carboxyl group content in EP3 was calculated from the nitrogen increase as $0.24 \mathrm{eq} / 100 \mathrm{~g} \mathrm{EP} 3$, e.g., $0.48 \mathrm{~mol}$ carboxyl group per phenylpropane unit.

\section{Molecular weight analysis}

Lignin is a complex polymer with a wide molecular weight distribution. A gel filtration profile of EP3 on a Sephacryl S-300 column (Fig. 4) showed one broad peak with molecular weight ranging from $10^{4}$ to $1.5 \times 10^{6}$. The weight-average molecular weight $\left(M_{w}\right)$ was calculated as $3.2 \times 10^{5}$, the number-average molecular weight $\left(M_{n}\right)$ was $2 \times 10^{4}$ and the molecular weight dispersity $\left(M_{w} / M_{n}\right)$ was 15.9 , indicating the polydisperse nature of EP3. The eluate in Fig. 4 was expediently collected into 4 fractions, EPS1, EPS2, EPS3, and EPS4, according to the order of elution. The approximate molecular weight of EPS1, 2, 3, and 4 were $1.1-1.5 \times 10^{6}, 4-11 \times 10^{5}, 1-4 \times 10^{5}$ and $1-10 \times 10^{4}$, respectively. While EPS4 showed the highest anti-HIV activity of the 4 fractions, ${ }^{4)}$ each fraction showed almost the same immunological activities as those of EP3 both in the activation of macrophages and the proliferation of bone marrow cells (data not shown).

\section{Identification of active substance in $E P 3$}

As described above, EP3 is composed of $81.1 \%$ water-solubilized lignin, $3.2 \%$ protein and $12.2 \%$ carbohydrate, each being tightly linked. To clarify which component of EP3 is responsible for the immunostimulating and antiviral activities, assays were done with 1) protein-digested EP3 (EP3-PR), 2) carbohydrate-eliminated EP3 (EP3-KL), and 3) lignin-decomposed EP3 (EP3-DL). EP3-PR and EP3-KL showed identical or rather superior immunological activities to EP3, while

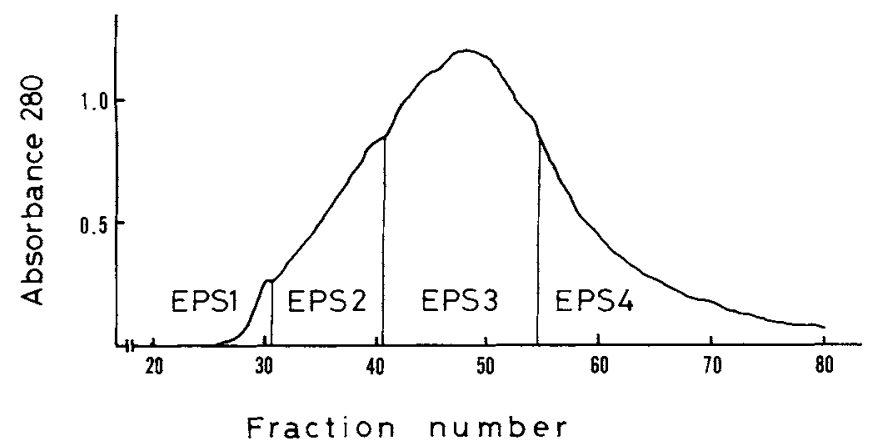

Fig. 4. Elution and Fractionation of EP3 from Sephacryl S-300 Column.

EP3 was eluted with $50 \mathrm{~mm}$ phosphate-Na buffer (pH 7.2) from a Sephacryl S-300 $(50 \mathrm{~mm}$ i.d. $\times 780 \mathrm{~mm}$; bed volume $1530 \mathrm{ml}$ ). Each fraction was $19.8 \mathrm{ml}$. They were divided into 4 fractions by the order of elution. 

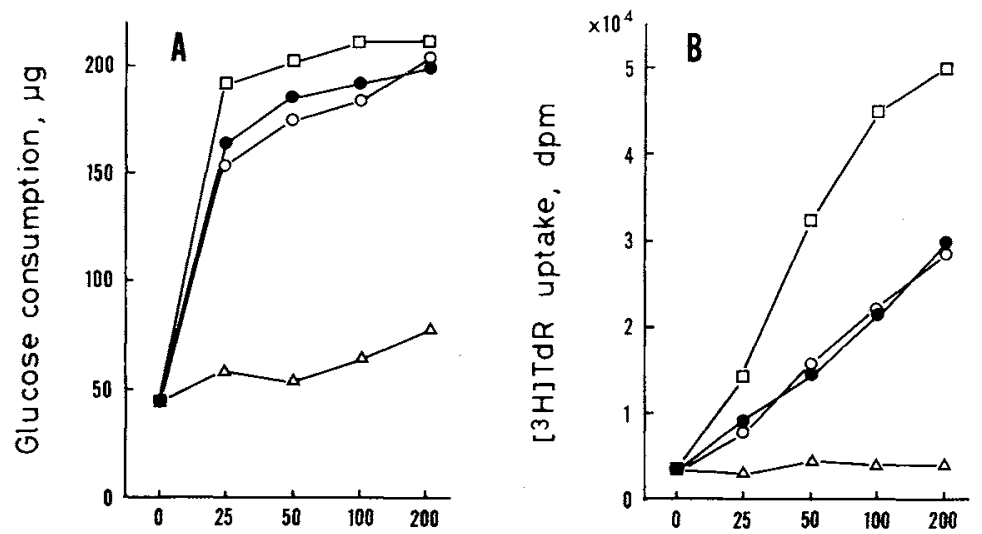

Concentration $(\mu \mathrm{g} / \mathrm{ml})$

Fig. 5. Effects of Protein Digestion (EP3-PR, O-O), Sugar Elimination (EP3-KL, $\square-\square$ ), and Lignin Degradation (EP3-DL, $\triangle-\triangle$ ) of EP3 $(-O)$ on $(A)$ Glucose Consumption of Cultured Murine Peritoneal Macrophages and (B) $\left[{ }^{3} \mathrm{H}\right]$ Thymidine Uptake of Murine Bone Marrow Cells.

(A): Peritoneal resident macrophages $\left(10^{5}\right)$ were cultured with various concentrations of samples on a 96 -well microplate at $37^{\circ} \mathrm{C}$. On day $4,25 \mu \mathrm{l}$ of culture supernatant was collected and glucose content was determined by the glucose oxidase method.

(B) Bone marrow cells $\left(1.5 \times 10^{5}\right)$ were cultured in the same way. On day $4,0.2 \mu \mathrm{Ci} / \mathrm{well}$ of $\left[{ }^{3} \mathrm{H}\right] \mathrm{TdR}$ was added, and incorporated radioactivity was counted.

Table I. Effects of Protein Digestion (EP3-PR), Sugar Elimination (EP3-KL), and Lignin DEgRadation (EP3-DL) OF EP3 ON HIVSPECIFIC ANTIGEN EXPRESSION ON HIVINFECTED MT-4 CELLS

\begin{tabular}{crrrr}
\hline & \multicolumn{4}{c}{ HIV-Ag positive cells $\%$} \\
\cline { 2 - 5 }$\mu \mathrm{g} / \mathrm{ml}$ & EP3 & EP3-PR & EP3-KL & EP3-DL \\
\hline 100 & $<2$ & $<2$ & $<2$ & 16 \\
50 & $<2$ & $<2$ & $<2$ & 30 \\
25 & 5 & $<2$ & $<2$ & 34 \\
12.5 & 48 & 19 & 7 & 38 \\
0 & $>90$ & & &
\end{tabular}

MT-4 cells were infected with HIV for $1 \mathrm{hr}$, and after washing with medium, infected cells $\left(3 \times 10^{5}\right)$ were cultured with samples on a 24 -well microplate at $37^{\circ} \mathrm{C}$. On day 4 , the expression of HIV antigens on HIV-infected MT-4 cells was determined by the indirect immunofluorescence using anti-HIV antibody positive plasma.

EP3-DL lost its activities considerably in the glucose consumption of macrophages (Fig. $5 \mathrm{~A})$, the thymidine uptake of bone marrow cells (Fig. 5B), and the morphological change of macrophages (data not shown).
Furthermore, the same tendency was observed in anti-HIV activity. As shown in Table I, EP3 completely inhibited the HIV-antigen expression of HIV infected MT-4 cells at concentrations of $\geq 50 \mu \mathrm{g} / \mathrm{ml}$. Although EP3-PR and EP3-KL showed anti-HIV activity at concentrations of $\geq 25 \mu \mathrm{g} / \mathrm{ml}$, EP3-DL did not have any apparent activity at concentrations up to $100 \mu \mathrm{g} / \mathrm{ml}$. The same result was observed in the inhibition of HIV-induced cytopathic effects (data not shown). These results showed that the immunoactive and antiviral substance in EP3 was a polycarboxylated water-solubilized lignin itself.

\section{Discussion}

EP3, the purified fraction from LEM, has been reported to augment glucose consumption of macrophages, induce proliferation of bone marrow cells, ${ }^{8)}$ and inhibit replication of HIV in vitro. ${ }^{4)}$ And further EP3 was shown to induce a morphological change (spreading) of macrophages. 


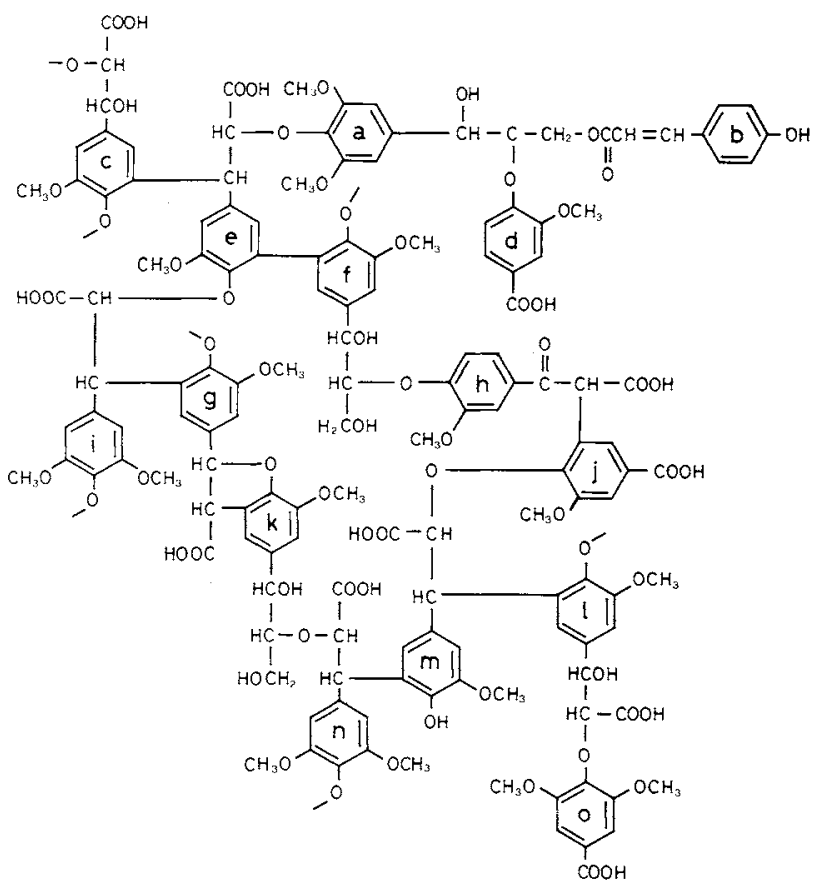

Fig. 6. Structural Features of the Water-solubilized Lignin in EP3.

In this study, we investigated the chemical structure and characteristics of EP3 and confirmed that the major portion of EP3 was the water-solubilized lignin. Based on our experimental results, we present tentative structural features of the water-solubilized lignin in EP3 (Fig. 6). The characteristics are summarized as follows: 1) It has many condensed structures between the ortho-position of phenolic oxygen in aromatic rings and the $\alpha$-carbon (benzyl position by lignin notation) of the phenylpropane side chain (nuclei $c-e, g-i, l-m$, and $m-n)$, since it yields few aldehydes by alkaline nitrobenzene oxidation (only nuclei $a$ and $h$ give aldehyde), 2) it has a considerable amount of carboxyl groups at the $\gamma$-position of the lignin side chain $(0.48 \mathrm{~mol}$ carboxyl group/ phenylpropane unit), 3) it has some benzoic acid structures which have never been reported in native lignin (nuclei $d, j$, and $o$ : nuclei $d$ and $o$ give benzoic acid by alkaline nitrobenzene oxidation), 4) it has a low content of free phenolic hydroxyls $(0.05 \mathrm{~mol} /$ phenylpropane unit: nuclei $b$ and $m$ have free phenols), 5) it remains a cinnamic acid ester (nuclei $a-b$ ).
Lentinus edodes (shiitake; a kind of basidiomycete) is generally known to have ability to degrade wood lignin, ${ }^{21)}$ and sugar-cane bagasse used in the medium contains about $20 \%$ of lignin, ${ }^{22)}$ so it is obvious that extracellular enzymes of Lentinus edodes denature bagasse lignin oxidatively to give the watersolubilized lignin. We further investigated to find which component in EP3 is responsible for the activities, because EP3 contains proteins, carbohydrates, and the water-solubilized lignin. Neither digestion of proteins nor elimination of sugars affected the immunological and antiviral activities, while degradation of lignin in EP3 caused an obvious decline of both activities. Therefore the water-solubilized lignin in EP3 was proved to be the principle of these immunological and antiviral activities.

Various polysaccharides which have an antitumor activity and immunological activities have so far been isolated from fruit bodies or mycelia of some basidiomycetes. ${ }^{23-25)}$ For example, lentinan, ${ }^{23)}$ which is the immunoactive $\beta$-1,3-glucan, was isolated from the fruit body of Lentinus edodes. Our previous idea 
that the immunoactive component in LEM was either polysaccharides or glycoproteins ${ }^{7,81}$ was completely contradicted by the discovery of this lignin derivative.

The molecular weight of the water-solubilized lignin in EP3 are widely distributed and the fractions EPS1, 2, 3, and 4 obtained by gel filtration chromatography of EP3 (Fig. 4) showed not only the same immunological activities as those of EP3 but also completely identical IR spectra to EP3. These results strongly suggest that the water-solubilized lignins in EP3 have almost the same structural characteristics except molecular sizes, and the immunological activities would be independent of their molecular sizes. In our previous work, the anti-HIV activity of EPS4, the lowest molecular weight fraction from EP3, was found superior to EP3 and the other fractions (EPS1, 2, and 3). ${ }^{4)}$ This suggest that while the immunological activities are independent of the molecular sizes, the antiviral activity depends on them and is dominant in the lower molecular weights ranging from $10^{4}$ to $10^{5}$. Accordingly, the mechanism of the immunological activities caused by the watersolubilized lignin might be different from that of the antiviral activity.

We have recently reported that lignosulfonate (LS) has the same immunological activities $^{26)}$ and anti-HIV activity ${ }^{27)}$ as EP3 in vitro. LS is a chemically sulfonated watersolubilized lignin from the waste liquor of acid sulfite process of woods, ${ }^{28)}$ and its structural features are different from the lignin in EP3. These results suggest that the immunological and antiviral activities of the water-solubilized lignins do not always depend upon the fine chemical structure, and it is presumed that these activities are common to various kinds of water-solubilized lignins. It remains to be studied if some factors common to a variety of the water-soluble lignins, such as polyanionic nature with highly hydrophobic architecture, cause the immunological and antiviral activities. The detailed structural presentation of this water-solubilized lignin with the new biological activities will be of interest for fur- ther development of lignin biochemistry.

\section{References}

1) N. Sugano, Y. Hibino, Y. Choji and H. Maeda, Cancer Lett., 17, 109 (1982).

2) H. Maeda, Y. Choji, Y. Hibino, S. Yasumura, A. Masumi and N. Sugano, Third Congress of the Federation of Asian Biochemists. Bangok, Thailand, 1983.

3) S. T. Tochikura, H. Nakashima, Y. Ohashi and N. Yamamoto, Med. Microbiol. Immunol., 177, 235 (1988).

4) H. Suzuki, A. Okubo, S. Yamazaki, K. Suzuki, H. Mitsuya and S. Toda, Biochem. Biophys. Res. Commun., 160, 367 (1989).

5) A. Shirohata, K. Mori, K. Kishida, I. Maruyama and K. Suzuki, Abstracts of Papers, the Annual Meeting of the AIDS Kenkyuukai, Matsue, July, 1989 , p. 63

6) Y. Mizoguchi, H. Katoh, K. Kobayashi, S. Yamamoto and S. Morisawa, Gastroenterologia Japonica, 22, 627 (1987).

7) H. Suzuki, H. Saito, A. Okubo, S. Yamazaki and S Toda, Igaku no Ayumi, 138, 441 (1986).

8) H. Suzuki, A. Okubo, S. Yamazaki and S. Toda, Jpn. J. Gastroenterol., 85, 1430 (1988).

9) N. Sugano, Y. Choji, Y. Hibino, S. Yasumura and H. Maeda, Cancer Lett., 27, 1 (1985).

10) T. Harada and T. Kanetaka, Kan-Tan-Sui, 14, 327 (1987).

11) L. G. Borchardt and C. V. Piper, Tappi, 53, 257 (1970).

12) R. L. Whistler, J. Bachrach and P. R. Bowman, Arch. Biochem., 19, 25 (1948).

13) O. Goldschmid, Anal. Chem., 26, 1421 (1954).

14) K. Iiyama and A. F. A. Wallis, Wood Sci. Technol., 22, 271 (1988).

15) K. Iiyama and T. B. T. Lam, J. Sci. Food Agric., in press.

16) T. B. T. Lam, J. Hirose, K. Iiyama and J. Nakano, Mokuzai Gakkaishi, 32, 44 (1986).

17) K. Iiyama and A. F. A. Wallis, Appita, 41, 442 (1988).

18) A. Björkman, Svensk Papperstidn., 59, 477 (1956).

19) T. Kondo, K. Mizuno and T. Kato, Bull. Natl. Grassl. Inst., 35, 55 (1986).

20) T. P. Shultz and M. C. Yempleton, Holzforschung, 40, 93 (1986).

21) H. Ishikawa, T. Oki and Y. Senba, Mokuzai Gakkaishi, 29, 280 (1983).

22) A. Kato, J. Azuma and T. Koshijima, Holzforschung, 38, 141 (1984)

23) G. Chihara, Y. Maeda, J. Hamuro, T. Sasaki and W. Fukuoka, Nature, 222, 687 (1969).

24) P. P. Singh, R. L. Whistler, R. Tokuzen and W. 
Nakahara, Carbohydr. Res., 37, 245 (1974).

25) Y. Sone, M. Kakuta and A. Misaki, Agric. Biol. Chem., 42, 417 (1978).

26) H. Suzuki, K. Iiyama, A. Okubo, S. Yamazaki and S. Toda, Agric. Biol. Chem., 53, 1197 (1989).
27) H. Suzuki, S. T. Tochikura, K. Iyama, S. Yamazaki, N. Yamamoto and S. Toda, Agric. Biol. Chem., 53, 3369 (1989).

28) J. Geier, Wood Sci. Technol., 19, 289 (1985). 